\title{
TEXT Editorial
}

\section{The quality of academic manuscripts}

We could start by saying that we have heard from other editors of refereed journals that the quality of academic writing seems to be at an unusually low standard but that we are pleased to say the same is not observable in contributions received at the office of TEXT...

We could start by saying that in the old days academics used to know how to write academic prose, that it was once a required competance, and that now it has become a lost art. We would need to do much more research to establish that (and it would surely make a great article for $T E X T$, or a book)...

We might start by blaming primary school teachers who no longer entrench in us the basic rules of grammar and punctuation, nor a logical sense of formatting and layout, nor how to construct an effective argument (perhaps this is where the real problem lies)...

The fact is, however, that TEXT receives occasionally (in common with other publications in academic areas) poorly-written MSS from people working at the so-called highest levels of written communication in our culture - i.e. university-employed or -enrolled writers.

There are many things to say about this phenomenon. It's well-known in fiction publishing that some respected and some big-selling creative writers - with national and international reputations - dish up exceedingly poor MSS. They rely on editors to tame wild spelling and punctuation... and even wild expression of ground-breaking ideas.

It's ironic that at a time when research quantum systems give no recognition to the work of editors of refereed journals and of monograph collections, these editors are often the cause of unpublishable MSS becoming worthwhile contributions to a discipline.

Various creative writers, alongside various academic writers, keep their MSS secret; these documents are an embarrassment to them, only offered up to the select few editors who deal with them and keep silent. Once published, these MSS are deleted from the author's computer. In the past, puff-chested writers saw their paper MSS as sacred objects, and sold them to the highest bidders.

But the system works because recognisable to editors today are not so much the minutiae of the commas and colons, the 'weird' or 'wierd' spellings, the failure to reference logically or consistently, the failure to reference at all, the inability to structure and deliver an argument engagingly or persuasively, etc. What gets recognised is the potential of the work to find its premium articulation.

Writing - of every kind - is a process of ever-inching towards an ultimate product.

However, there are refereed journals that don't publish a work unless the MS finds its own way to print-ready quality. In other words, the referees tell the 
author that the expression throughout needs to be brought up to academic standard. There are writing services that offer such dealing with a MS. Still there remains the question related to workers in academia who can't produce cogent, well-structured, error-free prose.

We are aware of our own undergraduate students - those who graduate without having attained perfect (or near-perfect) expression in academic writing. We are aware also of how some of them go on to postgraduate studies and still have difficulty producing a text which is elegant in all it parts and delivery. We are aware of our own dicey MSS - those that another's eye looks over and justifiably finds fault with.

So, why don't undergraduate students produce essays that read like the published academic articles they have studied in order to research those essays? Why don't research higher degree students produce dissertation writing that is structured and expressed like the research articles they have consulted and analysed? Why don't academics produce research article MSS that are as polished and stylish as those cited in their bibliographies?

Maybe there has been a breakdown of the mimetic in the academic culture. While we don't value so greatly (as did the past) the handed-down ideas, concepts and perceptions of previous generations, we still value the cogency and exactness of the expression those old ideas were couched in. While we nurture innovation and creativity in research thinking, we don't have the same free-wheeling attitude towards academic expression of that thinking. In fact, $T E X T$ has published some wilder expressions of newer ideas - in the digital, fictocritical and poetry areas, for example - and has generally encouraged use of cross-media illustration, cross-genre expression and cross-arts investigation, etc. But still, when it comes down to making sense, academic writing must convey its intentions hopefully clearly, hopefully exactly, and hopefully engagingly.

Yet, hoping your MS will make sense is not enough. Fully making it make sense is the start of hoping.

(In the above, there's at least one spelling error, four grammatical infelicities and a corrupt colon. Did you find them?)

\section{This issue}

Among the various MSS submitted to TEXT over the past twelve months, these nine have made their way through the writing, rewriting, refereeing, rerewriting and editorial process, and now are ready for you to read. As (quite) often happens, they seem to share some common concerns - something in the zeitgeist, perhaps, that makes its way to the minds and word processors of several writing academics at the same time. The issue expressed by many of the articles in the current TEXT is creative writing and/as research. Jeri Kroll draws on her recent research project to explore the exigencies of working as a creative writer within the university system, with all its competing priorities. Christine Owen and Catherine Cole each trace out some of the principles involved in writing as research, and ways of engaging as writers with the wider academy. Paul Magee and Francesca Rendle-Short model modes of research for creative writers: Magee detours by way of Kierkegaard, Jameson and Pushkin to gesture towards an approach that is, effectively, practice-led research, while RendleShort playfully weaves creative and critical writing into a complex, but single, body, 'practising' the work of practice-led research. Sue North teases out the basis for a serious problem faced by the discipline of creative writing - how to 
be taken seriously in the academy - and argues for the value of creativity as a mode of social understanding. The remaining essays turn attention to the ongoing issues faced by those of us who work as writing/teaching academics. Gay Lynch uses an extended metaphor to compare the discourses and the actualities attached to a particular cohort of creative writing students - those she calls 'economy-class passengers returning midlife from the world of work'. Gerry LaFemina discusses the complexities of teaching poetry, and of instilling in students a passion not only for writing, but for rewriting and editing and reworking until a poem realizes itself (in some ways, perhaps, anticipating the thrust of this editorial, and the urgency of the need for all writers to make writing work). Miriam Sved approaches the issue of teaching writing from the other end of things, reviewing five books produced in writing higher degrees programmes in Australia: dissertations that have travelled successfully from the examiner's to the publisher's desk. Adding to these excellent essays are the poems and reviews that in different ways speak out the experience of creative writing academics. Cameron Fuller and Rob Walker each focus on aspects involved in making a work of writing, producing a sort of meta-poetry that wonderfully exemplifies what it is, or can be, to write. Jondi Keane extensively reviews a publication that should be on the shelves of every writing academic, the recent Media International Australia that focused on practice-led research, and adds to the ways of understanding such work that are begun and extended by the contributors to that journal.

Next month, members of the AAWP and contributors to and readers of TEXT will meet in Brisbane for the 11th annual conference of the Association: Perilous Adventures: Creative Writing Practice and Research in the Higher Degree and Beyond. We encourage all the delegates to that conference to review their papers during the summer break, and submit for consideration any work they consider has relevance to their fellow writing academics.

Nigel Krauth

Jen Webb

\section{TEXT}

Vol 10 No 2 October 2006

http://www.griffith.edu.au/school/art/text/

Editors: Nigel Krauth \& Jen Webb

Text@griffith.edu.au 